\title{
Potency of PR controller for multiple harmonic compensation for a single-phase grid connected system
}

\author{
D. Sattianadan', Soumen Gorai ${ }^{2}$, G. R. Prudhvi Kumar ${ }^{3}$, S. Vidyasagar 4 , V. Shanmugasundaram ${ }^{5}$ \\ 1,2,3,4 SRM Institute of Science and Technology, Kattankulathur, Chennai, Tamilnadu, India \\ ${ }^{5}$ Sona College of Technology, Salem, Tamilnadu, India
}

\begin{tabular}{l} 
Article Info \\
\hline Article history: \\
Received Oct 9, 2019 \\
Revised Feb 29, 2020 \\
Accepted Mar 18, 2020 \\
\hline
\end{tabular}

Keywords:

Fast fourier transform (FFT)

Grid synchronisation

Phase locked loop (PLL)

Proportional resonant (PR)

controller

Total harmonics distortion

(THD)

\begin{abstract}
Harmonics and grid synchronization are one of the major problems faced when dealing with a single-phase system. The development of technology in the PV system makes the consumer to use it in a wide range. The power transferred from PV to grid needs DC to AC conversion process which is done by static devices operating with the higher frequencies that causes the harmonics in the grid connected system. The main aim of the paper is to implement grid synchronization and reduce total harmonic distortion in a single-phase grid connected system. The design of LCL filter is addressed in this paper which depends on current ripple, filter size and switching ripple attenuation. In order to account the harmonic content, the FFT analysis is made both in analysis and Matlab Simulink. The Proportional Resonant (PR) controller is developed and work along with LCL filter for reducing the harmonic content. The stability of the system with PR is analyzed using root locus and bode plots and results are compared with PI controls. The result shows that PR controller performs better compared to the PI controller for reducing the harmonic content present in the single-phase system and for improving the system stability.
\end{abstract}

This is an open access article under the CC BY-SA license.

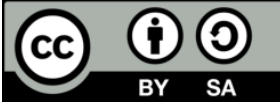

\section{Corresponding Author:}

D. Sattianadan,

Departement of Electrical and Electronics Engineering,

SRM Institute of Science and Technology, Chennai.

Email: sattia.nadan@gmail.com

\section{INTRODUCTION}

In the recent energy trends, there is a tremendous increase in the demand for renewable energy. Solar being the most abundant source, Photovoltaic systems can be used as a replacement for conventional energy sources. To Study the characteristics and to adjust the parameters of PV system, it must be modelled properly before connecting to the network. The author presents a method to model a solar cell using equivalent circuit of solar cell. This model for PV system has been developed based on a mathematical equation that shows the variation of output of the solar cell with varying temperature, irradiation, series resistance and shunt resistance [1-3]. The major disadvantage of solar energy is the low usable energy as the output, which can be overcome by using a Maximum Power Point Tracking (MPPT) technique. Many MPPT techniques has been developed in the recent years among which the most commonly used MPPT technique is Perturb and Observe method because of its ease for implementation [4-6]. The ANN based controllers with HILL climbing algorithm reaches the maximum power point in a fast manner and increase the output of the PV. Based on the values of solar insolation and temperature, the output of reference voltage has been determined by ANN and the output of the controller is further optimized by HILL climbing algorithm [7]. The development of modern controllers increases the output of PV system effectively 
irrespective of climatic condition. The Sliding Mode Controller (SMC) is best suited for sliding surfaces of maximum power point tracking (MPPT) of photovoltaic (PV) panel using a buck converter. The input to the sliding mode controller is given by voltage reference estimator which estimate the reference voltage under constant irradiation. Under partial shadow condition a partial shadow algorithm is used to effectively track maximum power $[8,9]$. The solar power has been transmitted to the grid through by power converters and these power converters consist of a single-phase Voltage Source Inverter (VSI) with L filter operated at high switching frequency to reduce harmonics. However, with the use of an LCL filter, the total harmonics can be reduced to fit in the acceptable range (3-6\% for PR controller). The Phase locked loop (PLL) has been employed to map out the phase of an output signal to the phase of the input signal. The voltage and current derived from grid fed to PLL which controls the switching logic of the inverter through SPWM to get a synchronized voltage. Different types of PLL configuration and their functionality has been discussed in [10, 11]. Ref. [12] provides an apprach for modelling and design of Synchronous Reference Frame Phase-Locked Loop (SRF PLL). Different control techniques have been adopted to the intermediate DC/DC buck converter interfaces the PV source and the DC-AC inverter. The control of single-phase current source inverter-based grid tie photovoltaic (PV) system has been addressed in [13]. A current control technique for a single-phase grid connected DC/AC inverter which is used in Photovoltaic power conditioning system has been presented in [14]. The single-phase sinusoidal pulse width modulated (SPWM) inverter control with modified unipolar switching is presented in $[15,16]$. The $\mathrm{d}-\mathrm{q}$ theory has been utilized for calculation current reference of the parallel inverter to control the active and reactive power of distributed sources in the micro grid $[17,18]$. Due to the simple design and excellent reference tracking capability of the PR controller makes the controller used in the wide range of applications [19-23]. In this paper, a performance analysis of a single-phase grid connected PV system with a Proportional Resonant (PR) controller is presented. This analysis includes a model with a single level VSI connected to the LCL filter to reduce the harmonic content and this level is reduced further by using a PR controller, which works based on the error signal derived between grid and PV system. This work carried out on a single phase $220 \mathrm{~V}, 50 \mathrm{~Hz}$ system with PV system to validate the potency of PR controller on harmonic reduction and the PLL techniques ensures successful grid synchronization for the practical applications.

\section{PROPOSED MODEL}

The implementation of Renewable energy sources like Solar, Wind and Fuel cells in the network needs AC to DC and DC to AC conversion process. The static switchs operating with higher frequency are involved in this conversion process which induces harmonics in the system. The Alternating signals contain harmonics, which are harmful for the network as they cause a spike in Zero Sequence Current, especially third harmonics. Hence, it is necessary to eliminate Total Harmonics Distortions to an acceptable level, as prescribed by IEC-61642 to be within 3-6\%. When injecting single phase power to the grid, the frequency and phase of the network signal matches with the grid. In order to achieve synchronization, the phase of the grid must be derived, which is done using a Phase Locked Loop. In this paper, a Second Order Generalized Integral (SOGI)-PLL has been used for grid synchronization which serves as Quadrature Signal Generator. Low pass filter and frequency phase shift generator are other components of SOGI-PLL which are used to enhance the performance of multiplier-based phase detector. The first order Low pass filter eliminates the high frequency parts from Phase detector output. A Voltage Controlled Oscillator is used to shift the frequency of the output signal based on a reference frequency $\omega_{c}$. The output of the Phase detector gives the phase angle difference between PLL oscillator voltage and input (reference) voltage. Figure 1 shows the fuctional diagram of an electrical network with PR controller used for reduction in harmonics and grid synchronisation. A DC link voltage is used as a voltage source for the inverter and maintained at $400 \mathrm{~V}$. An H-bridge Inverter consists of 4 - MosFet switches which generate a distorted sinusoidal output of about $310 \mathrm{~V}$, with ripples and distortions. This distorted signal has been supplied through a LCL filter to smoothen the curve, reduce the distortions. Voltage is derived from the grid and supplied to the PLL to obtain phase of the grid $\theta$. Meanwhile, grid signals (Vgrid, Igrid) are tapped and transformed to $\alpha-\beta$ form. An error signal has been generated by comparing Vgrid with the desired value of voltage (Vref $=310 \mathrm{~V})$. This error signal is fed to a PR controller which produces resonant high frequency damping, eliminating harmonics distortions. With the help of the controller output the switching logic of the Inverter is controlled, based on SPWM technique. Therefore, synchronisation of the grid is achieved with reduced harmonics. 


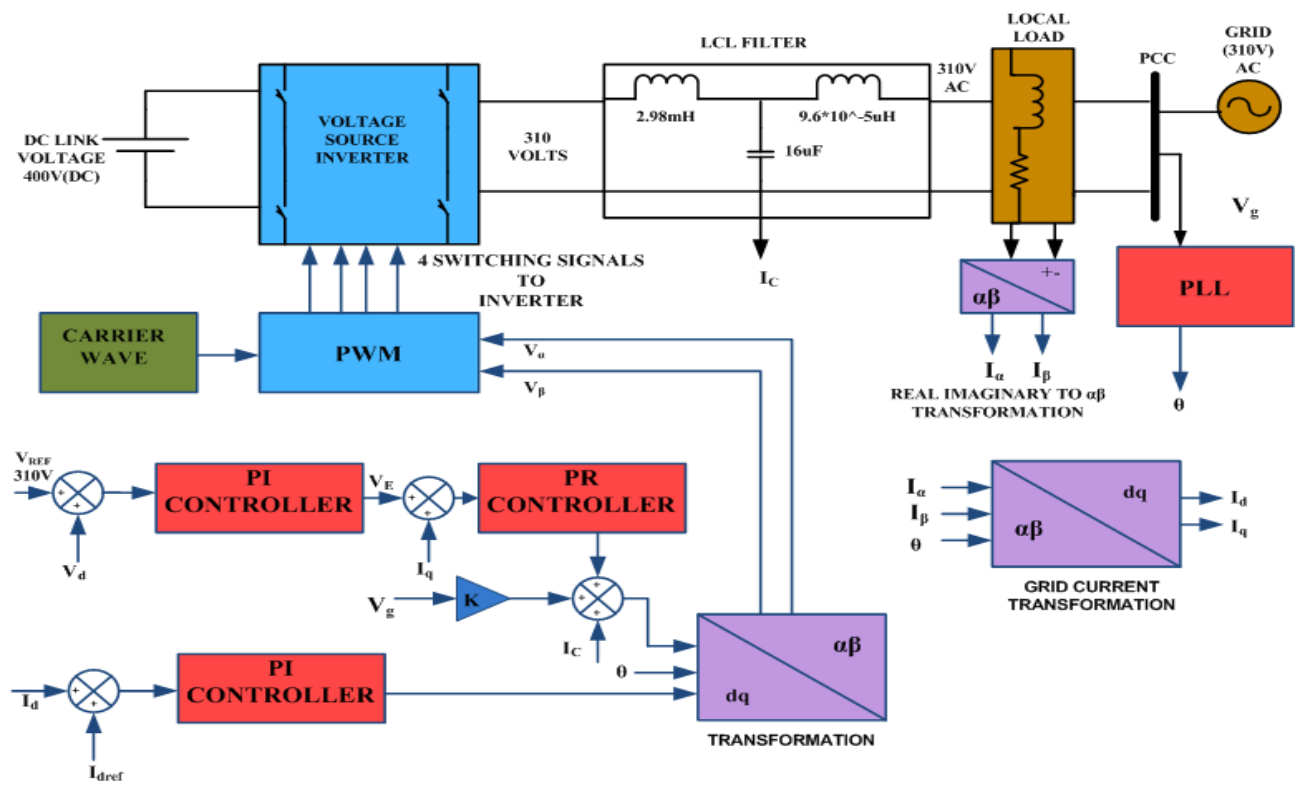

Figure 1. Proposed Model- Single Phase Grid Connected System with PR Controller

\section{DESIGN OF LCL FILTERVFOR VSI OUTPUT SMOOTHING}

VSIs are widely used for the generation of alternating voltage or current (from a DC input) in high and medium power industries. A single-phase full bridge Voltage Source Inverter uses 4 switches to obtain an alternating output. These switches are power electronic devices such as MosFet, IGBTs, which is preferred over other devices because of its ease for control. The switches operate alternatively to conduct bidirectional current and produce a sinusoidal output. In order to obtain the switching logic of the inverter switches, a Sinusoidal Pulse Width Modulation technique (SPWM) has been used. In SPWM technique, the Signal Modulation Wave is compared to a high frequency carrier wave of known peak. When the frequency of the carrier wave is greater than that of the modulation wave, a positive DC up rail is obtained and vice-versa. Due to the comparison of high frequency wave with a lower frequency one, some components of the higher frequency wave get added which gives rise to harmonics in the network. In order to remove the unwanted distortions, the signal is applied to a LCL Filter which is designed according to current ripple, filter size and switching ripple attenuation, to reduce the harmonics. LCL filter act as inferface between the PV system to the utility grid for rdecing the horminic content and improve the power quality which has been injected to the grid. The design of LCL filter already discussed in [24-26]. The same design procdure has been used here to calculate the nominal values of LCL filter. The value of inverter side inductor, $\mathrm{L}_{1}$ is calculated using (1), where, m.f denotes the inverter modulation factor for SPWM inverter and $V_{\text {in }}$ stands for inverter output voltage.

$$
L_{I}=\frac{2 V_{i n}}{3 I_{m}}(1-m . f)(m . f) T_{s w}
$$

Maximum ripple occurs at maximum peak to peak current (2) for a modulation factor of 0.5.

$$
\begin{aligned}
& \Delta I_{M}=\frac{V_{\text {in }}}{6 f_{s w} L_{I}} \\
& L_{I}=\frac{V_{\text {in }}}{6 f_{s w} \Delta I_{m}}
\end{aligned}
$$

Where $\Delta I_{m}$ denotes maximum current through inductor. Therefore, for $\mathrm{V}_{\mathrm{in}}=400 \mathrm{~V}$, the inductor value is calculated as $2.93 \mathrm{mH}$ (3). The value of maximum current is obtained using. (4).

$$
I_{m}=\frac{P_{N}}{E_{N}}
$$

For a $10 \%$ ripple $\Delta I_{m}$ becomes $0.1 \mathrm{I}_{\mathrm{m}}$ which is calculated from the values of nominal power, $\mathrm{P}_{\mathrm{N}}$ and R.M.S voltage, $\mathrm{E}_{\mathrm{N}}$. The value of base impedance, $z_{b}$ is calculated using (5). 


$$
z_{b}=\frac{E_{N}^{2}}{P_{N}}
$$
using (6).

The value of base capacitance (7) is used to derive capacitor filter for $5 \%$ maximum power variation

$$
\begin{aligned}
& \mathrm{c}_{\mathrm{f}}=0.05 \mathrm{c}_{\mathrm{b}} \\
& c_{b}=\frac{1}{2 \pi * 50 * z_{b}}
\end{aligned}
$$

By allowing $5 \%$ power factor variation the value of filter capacitance, $\mathrm{C}_{\mathrm{f}}$ is calculated as $16 \mu \mathrm{F}$. Now considering a $20 \%$ attenuation factor the value of grid side inductor, $L_{2}$ for the desired attenuation factor $k_{a}$ and switching frequency $w_{\mathrm{sw}} 10 \mathrm{KHz}$ is calculated as $9.6 \times 10^{-5} \mu \mathrm{H}$ using (8).

$$
L_{2}=\frac{\sqrt{\frac{1}{k_{a}^{2}}}+1}{c_{f} w_{s w}^{2}}
$$

After performing the calculation, the obtained values for LCL filter connected to the grid are enlisted in Table 1.

Table 1. Values of LCL filter with Grid Parameters

\begin{tabular}{ccc}
\hline Grid frequency & $\mathrm{f}_{\mathrm{g}}$ & $50 \mathrm{~Hz}$ \\
\hline PWM carrier frequency & $\mathrm{f}_{\mathrm{sw}}$ & $10 \mathrm{KHz}$ \\
Nominal power & $\mathrm{P}_{\mathrm{N}}$ & $5 \mathrm{Kw}$ \\
Phase grid voltage & $\mathrm{V}_{\mathrm{g}}$ & $220 \mathrm{v}$ \\
DC link Voltage & $\mathrm{V}_{\mathrm{in}}$ & $400 \mathrm{v}$ \\
Inverter side inductor & $\mathrm{L}_{1}$ & $2.98 \mathrm{mH}$ \\
Grid side inductor & $\mathrm{L}_{2}$ & $9.6^{*} 10^{-5} \mu \mathrm{H}$ \\
Capacitor filter & $\mathrm{C}_{\mathrm{f}}$ & $16 \mu \mathrm{F}$ \\
\hline
\end{tabular}

\section{CONTROL STRUCTURE FOR PR CONTROLLER}

In order to achieve grid synchronisation, the phase angle of the grid must be obtained. Thus, a phase locked loop (PLL) technique has been implemented with a finite d-q transformation technique for the singlephase grid voltage. Figure 2 shows the control structure PR controller is designed for current control. The DC link voltage (Vd)is compared with a reference voltage (Vref) of $310 \mathrm{~V}$ and is then fed to a PI Controller. The PI controller generates an error signal which is compared to the quadrature Current obtained from the grid (Iq) and fed to the PR controller. PR with harmonic compensators function to reject the 3rd, 5th and 7th harmonics. The output of the PR is compared with the voltage from the grid $(\mathrm{Vg})$ and output of the LCL Filter (Ic) to generate E1. Meanwhile, Direct Current (Id) after comparing with a reference current (Iref $=0$ ), is fed to a PI controller. Thus, both the signals E1 and E2 along with $\theta$ (from PLL) is used to control the PWM of the VSI.

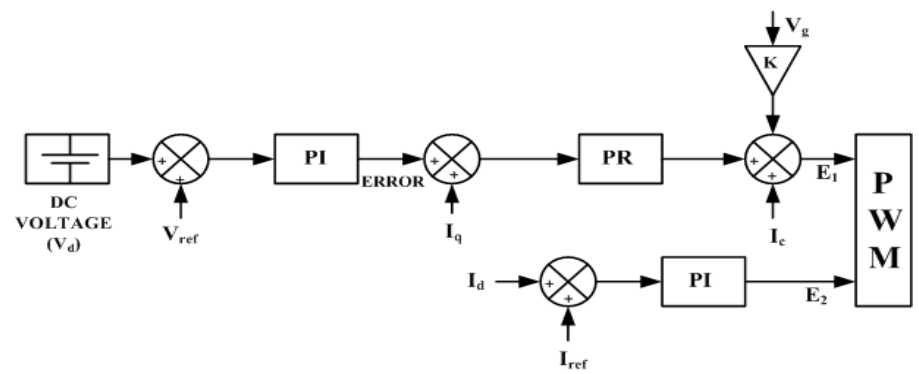

Figure 2. Control structure of the system

The PR controller consists of a resonant part that provides infinite gain at the AC frequency $\left(\mathrm{w}_{0}\right)$ and no phase shift and gain at other frequencies. Due to these resons the PR controller is used instead of the conventional PI controller. The transfer function for the PR controller is defined as: 
$G_{P R}(s)=k_{p}+k_{i} \frac{s}{s^{2}+w_{o}^{2}}$

An ideal PR Controller gives an infinite gain, although its transfer function suffers with stability problems (equation.9) which can be avoided by making the PR controller with finite gain shown in (10).

$$
G_{P R}(s)=k_{p}+k_{i} \frac{2 w_{c} s}{s^{2}+2 w_{c} s+w_{o}^{2}}
$$

To compensate the selective harmonics such as the $3^{\text {rd }}, 5^{\text {th }}$, and $7^{\text {th }}$ harmonics; several generalised integrators are cascaded as shown in Figure 3 and tuned to resonate at a desired frequency.

The transfer function for harmonic compensators can be written as:

$$
G_{h}(s)=\sum_{h=3,5,7} k_{i h} \frac{2 w_{c} s}{s^{2}+2 w_{C} s+\left(h w_{o}\right)^{2}}
$$

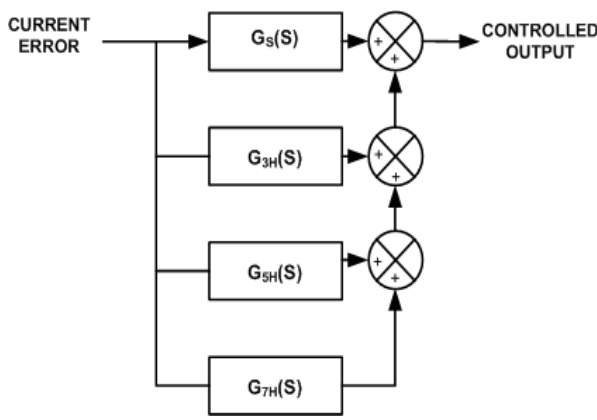

Figure 3. PR controller with cascaded harmonic compensators

\section{RESULTS AND DISCUSSION}

The main objective of the paper is to reduce the Total Harmonic Distortions that arise as a result of High Frequency switching devices like inverters. Although with the use of a LCL Filter the THD has been reduced to a certain level, it remained unfit for feeding to the grid, as per international standards. A PR controller is preferred over the conventional PI controller due to two major drawbacks of PI.

- $\quad$ The inability of PI to track a sine wave reference with zero steady-state error.

- PI has poor disturbance rejection capability.

In order to reduce the harmonics to an acceptable level, a PR controller with cascaded harmonic compensators was designed to eliminate the odd harmonics present in the system. In the Figure 4 the frequency response of the plant, controller and the overall system has been compared both with PI and PR controller. It is observed that, the difference is only at low frequency band for the overall system. By tuning the PR controller, the resonant peak occurring in the frequency response can be eliminated, where as in PI controller the peak still appears. In case of PR controller, the gain margin can be reduced. Since the PR controller has greater magnitude at fundamental frequency, it can track the reference with zero error.
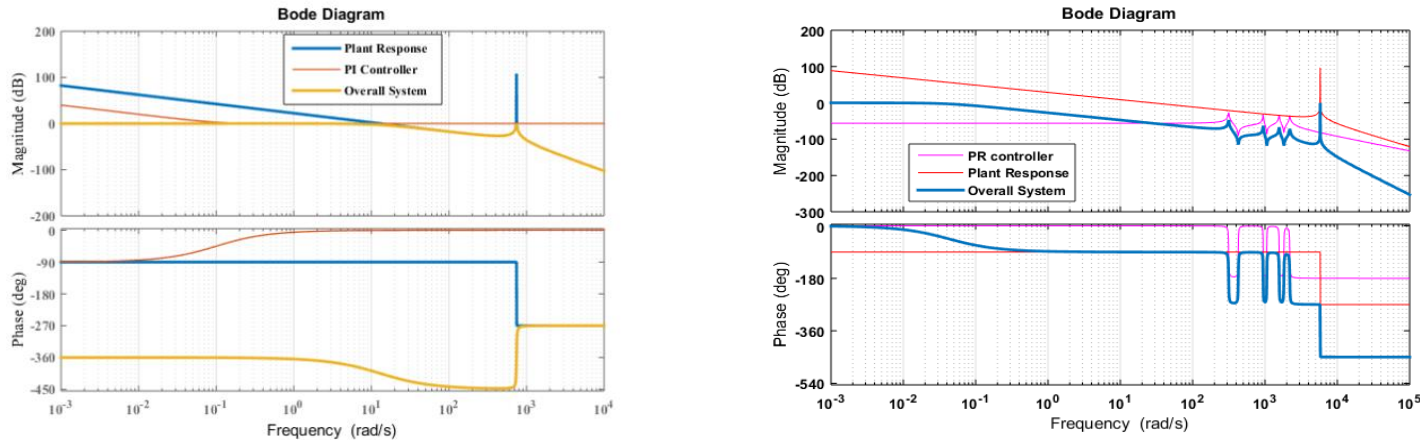

Figure 4. Frequency response of (a) PI Controller (b) PR controller

Potency of PR controller for multiple harmonic compensation for a single-phase ... (D. Sattianadan) 
Figure 5 (a), (b) shows the root locus were plot of the system with a PR and PI controller, it has been observed that the system is fully stable with PR controller as all points in the root locus analysis lied between break-in and break-away points along the Y-axis, whereas in case of PI controller, not all the points lie between break-in and break-away points which shows that the system is marginally stable with PI controller.
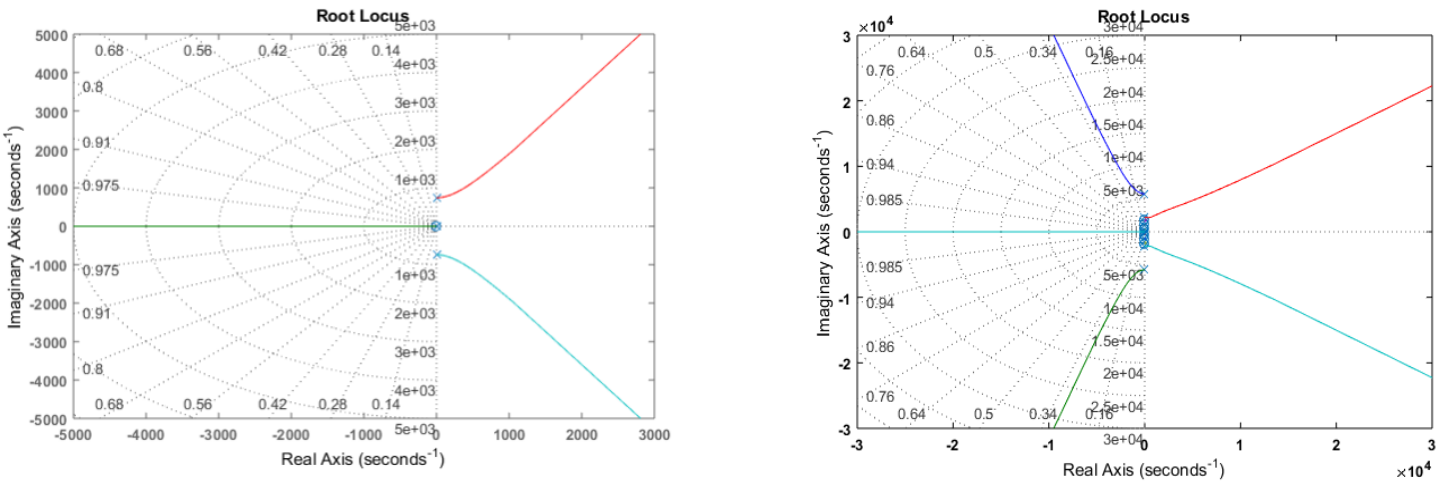

Figure 5. Stability analysis for (a) PI Controller (b) PR controller

With reference to the Figure 6. (a) the system is synchronised using a PR controller. Up to 0.04sec, the grid is not synchronised because the breaker is off and then the breaker is switched on after $0.05 \mathrm{sec}$ which makes the synchronisation possible whereas when grid synchronisation is done using PI controller shown in Figure 6. (b) the amplitude of both the voltages i.e. the inverter and the grid voltages are not synchronised which makes the system with PI controller unstable.
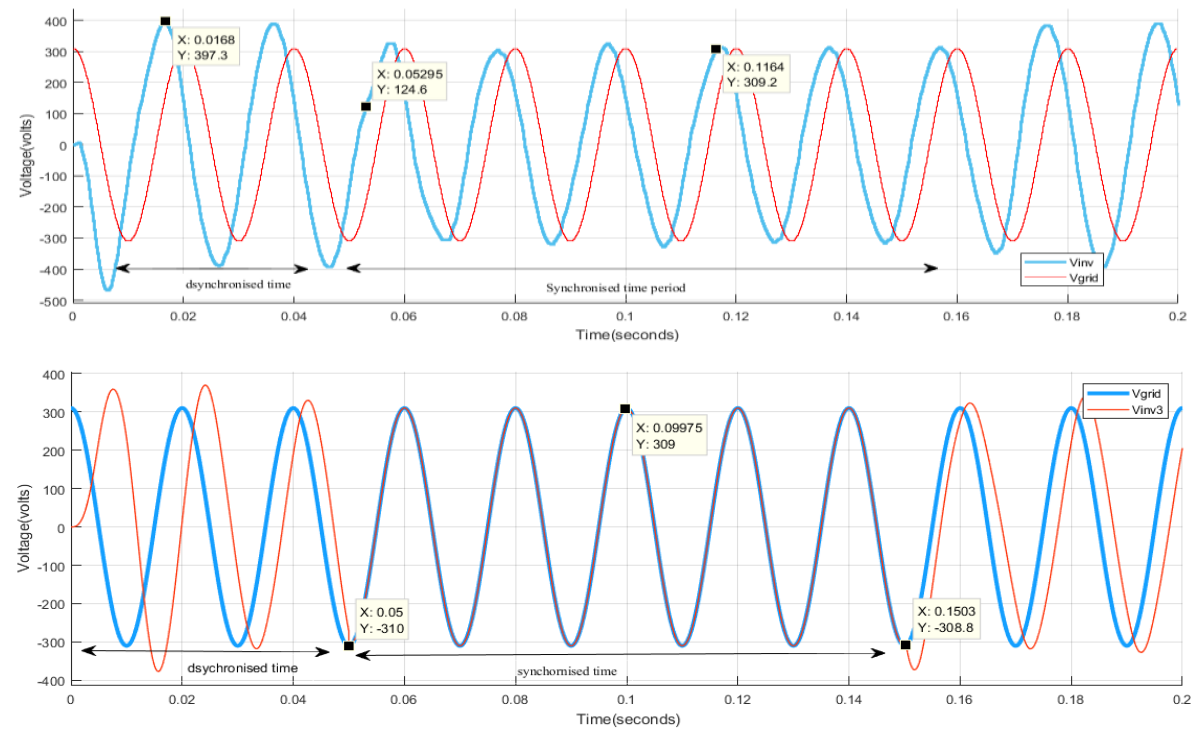

Figure 6. Grid synchronisation. (a) PR Controller (b)PI controller

The Fourier analysis of the system Figure 7. (a) connected with a PR controller is carried out along with MATLAB Simulink, and it is found that the Total Harmonics Distortions in the system after excluding the odd harmonics was reduced up to $4.66 \%$ for voltage and $0.92 \%$ for current where as in Figure 7 . (b) the THD is $6.16 \%$ for voltage and $5.76 \%$ for current using PI controller. Figure. 7.a shows that PR controller gives better performance compared to PI controller and also with the system having LCL filter with out PR controller. 


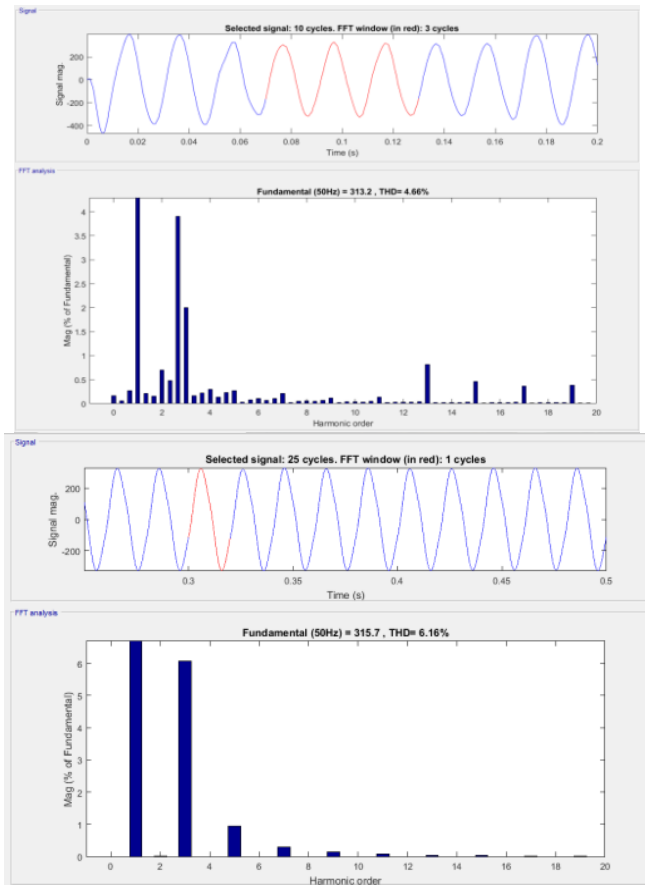

(a)

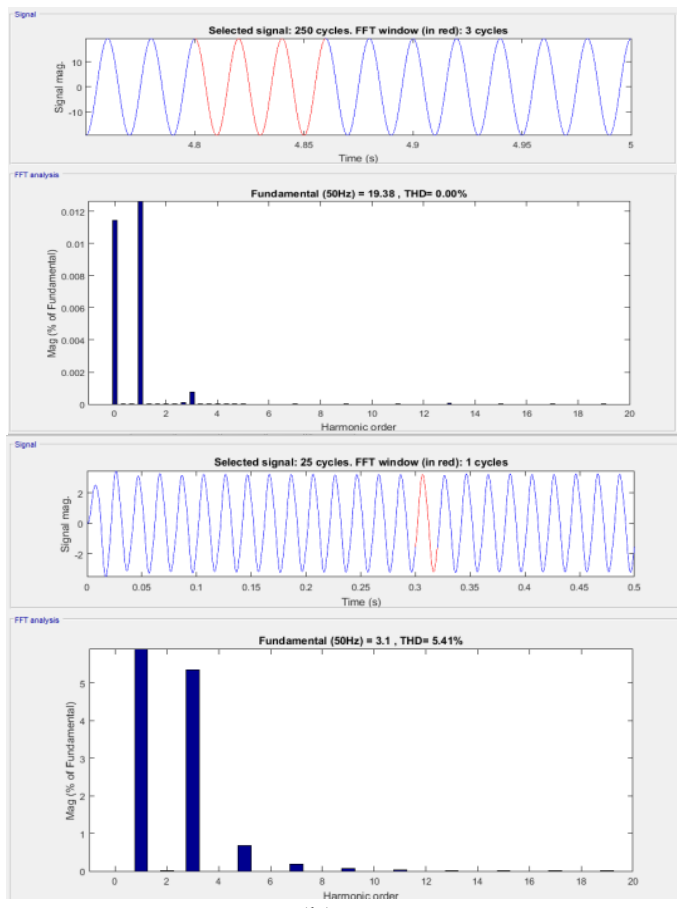

(b)

Figure 7. Current and voltage fourier analysis of system with (a) PR controller and (b) PIcontroller using MATLAB

\section{CONCLUSION}

The development of technology, compact in size, reduction of cost and polluction free of PV system enables the consumer to use the PV system in a wide range. The power transferred from PV to grid involes $\mathrm{DC}$ to $\mathrm{AC}$ conversion process which is done by static devices. These static devices operating with higher frequency which causes the harmonic in the low voltage distribution system. The design of LCL filter has been addressed in this paper which depends on current ripple, filter size and switching ripple attenuation. In order to account the harmonic content, the FFT analysis has been made analytically and using matlab Simulink. Results shows that current harmonic in the range of $6 \%$ and voltage harmonic in the range $6.5 \%$ which is not acceptable according to the international standard. Hence, it has been found that LCL filter alone is not sufficient to reduce the harmonic content present in the signal. In order to reduce the harmonic content, the PR controller has been developed and work along with LCL filter. To make the PR controller as robust, the cascaded harmonic compensator has been developed which reduce the 3rd, 5th, 7th harmonic at the great extent. The stability of the system with PR has been analysied using root locus and bode plots and results has been compared with PI controller. The results show that PR controller reduce the voltage harmoic to $4.66 \%$ and current harmonic to $0.92 \%$ which less than compared to PI controller.

\section{REFERENCES}

[1] J.P. Lee, B.D. Min, T.J. Kim, D.W. Yoo and J.Y. Yoo, "Design and Control of Novel Topology for Photo-Voltaic DC/DC Converter with High Efficiency under Wide Load Ranges," Journal of Power Electronics, vol.9, no.2, pp.300-307, Mar. 2009.

[2] Pooja Sahu, Deepak Verma, Dr. S Nema, "Physical Design and Modelling of Boost Converter for Maximum Power Point Tracking in Solar PV Systems," International Conference on Electrical Power and Energy Systems, pp.10-15, Dec 2016.

[3] W. Xiao, H.H. Zeineldin, "A Simple Approch to Modeling and Simulation of Photovoltaic Modules," IEEE Tranction on Sustainable Energy, vol.3, no.1, pp.185-186, 2012.

[4] M. A. Elgendy, B. Zahawi, and D. J. Atkinson, "Assessment of perturb and observe MPPT algorithm implementation techniques for PV pumping applications," IEEE Trans. Sustain. Energy, vol. 3, no. 1, pp. 21-33, Jan.2012.

[5] Subudhi, B., and Pradhan, R., "A Comparative Study on Maximum Power Point Tracking Techniques for Photovoltaic Power Systems," IEEE Trans. Sustain. Energy, vol. 4, no. 1, pp. 89-98, 2013.

[6] Sridhar. R, Vishnuram. P, Sattianadan. D, "Efficient Single Stage Photovoltaic Pumping System Using BLDC Motor with Grid Power Export," Journal of Solar Energy Engineering, vol-141, no. 5, 2019.

Potency of PR controller for multiple harmonic compensation for a single-phase ... (D. Sattianadan) 
[7] K. Ranjani, M. Raja, B. Anitha, "Maximum Power Point Tracking by ANN Controller for a Standalone Photovoltaic System," International Journal of Electronics and Communication Engineering, vol.8, no.3, pp.622626, 2014.

[8] Raseswari Pradhan, Bidyadhar Subudhi, "Double Integral Sliding Mode MPPT Control of Photovoltaic System," IEEE Transactions on Control Systems Technology, vol. 24, no.1, 2016.

[9] D. Sattianadan, V. Kalyanasundaram, S. Vidyasagar, Deepak Kumar Nayak Roopam Jha, "Maximum Power Point Tracking for a Grid Connected Photovoltaic System Using Sliding Mode Control," International Journal of Power Electronics and Drive System (IJPEDS), vol. 8, No. 4, pp. 1785-179 December 2017,

[10] Guan-Chyun Hsieh and James C, "Phase-Locked Loop Techniques-A Survey," IEEE Transactions on Industrial Electronics, vol. 43, No. 6, pp.609-615, December 1996.

[11] Yang Han, Mingyu Luo, Xin Zhao, Josep M. Guerrero, Lin Xu, "Comparative Performance Evaluation of Orthogonal-Signal-Generators-Based Single-Phase PLL Algorithms-A Survey," IEEE Transactions on Power Electronics, vol. 31, no. 5, 2016.

[12] Masoud Karimi-Ghartemani, Boon-Teck Ooi, Alireza Bakhshai, "Application of Enhanced Phase-Locked Loop System to the Computation of Synchrophasors," IEEE Transactions on Power Delivery, vol. 26, no. 1, pp.22-32, January 2011

[13] Ines Bourguiba, Azeddine Houari, Hamed Belloumi and Ferid KourdaControl of Single-Phase Grid Connected Photovoltaic Inverter," Proceedings of 2016 4th International Conference on Control Engineering \& Information Technology (CEIT-2016) Tunisia, Hammamet- December, 16-18,2016.

[14] Fu Zhongwen, Li Haishan, Huang Wenling, Hao Ruixiang, "A New Current Detecting Method based on d-q Transformation for Active Power Filter," IEEE conference, pp.2265-2268, 2002.

[15] Sachin Maheshri, Prabodh Khampariya, "Simulation of single phase SPWM (Unipolar) inverter," International Journal of Innovative Research in Advanced Engineering (IJIRAE), vol.1 no. 9, pp.12-18, October 2014.

[16] Souvik Dasgupta, Sanjib Kumar Sahoo and Sanjib Kumar Panda, "Single-Phase Inverter Control Techniques for Interfacing Renewable Energy Sources with Microgrid-Part I: Parallel-Connected Inverter Topology with Active and Reactive Power Flow Control Along with Grid Current Shaping," IEEE Transactions on Power Electronics, vol. 26, no. 3, pp.717-731, March 2011.

[17] C.T. Rim, N.S. Choi, G.C. Cho, G.H. Cho, "A complete DC and AC analysis of three-phase controlled-current PWM rectifier using circuit D-Q transformation,” IEEE Transactions on Power Electronics, vol.9, no.4, 1994.

[18] Papan Dey, Saad Mekhilef, "Current harmonics compensation with three-phase four-wire shunt hybrid active power filter based on modified D-Q theory," IET Power Electronics, vol.8, no.11, 2015

[19] Hanju Cha, Trung-Kien Vu and Jae-Eon Kim, "Design and Control of Proportional-Resonant Controller Based Photovoltaic Power Conditioning System”, IEEE conference, pp. 2198 - 2205, 2009.

[20] Changyue Zou, Bangyin Liu, Shanxu Duan, Rui Li, "Stationary Frame Equivalent Model of Proportional-Integral Controller in dq Synchronous Frame," IEEE Transactions on Power Electronics, vol. 29, no.9, 2014.

[21] Alon Kuperman, "Proportional-Resonant Current Controllers Design Based on Desired Transient Performance," IEEE Transactions on Power Electronics, vol.30, no.10, 2015.

[22] Kamyar Seifi, Mehrdad Moallem, “An Adaptive PR Controller for Synchronizing Grid-Connected Inverters," IEEE Transactions on Industrial Electronics, vol.66, no.3, 2019.

[23] Nayan Kumar, Tapas Kumar Saha, Jayati DeyControl, "Implementation, and analysis of a dual two-level photovoltaic inverter based on modified proportional-resonant controller," IET Renewable Power Generation, vol.12, no.5, 2018.

[24] LCL Filter Design and Performance Analysis for Grid-Interconnected Systems," IEEE Transactions on Industry Applications, Vol. 50, No. 2, pp 1225- 1231. March/April 2014.

[25] W. Yao, Y. Yang, X. Zhang, F. Blaabjerg and P. C. Loh, "Design and Analysis of Robust Active Damping for LCL Filters Using Digital Notch Filters," IEEE Transactions on Power Electronics, vol. 32, no. 3, pp. 2360-2375, March 2017.

[26] G. R. Prudhvi Kumar, D. Sattianadan, K. Vijayakumar, "A survey on power management strategies of hybrid energy systems in microgrid", International Journal of Electrical and Computer Engineering (IJECE), vol. 10, no. 2, pp. 1667-1673, April 2020. 